\title{
How asbestos drives the tissue towards tumors: YAP activation, macrophage and mesothelial precursor recruitment, RNA editing, and somatic mutations
}

\author{
Hubert Rehrauer $\mathbb{D}^{1} \cdot$ Licun $\mathrm{Wu}^{2} \cdot$ Walter Blum ${ }^{3} \cdot$ Lazslo Pecze $^{3} \cdot$ Thomas Henzi $^{3} \cdot$ Véronique Serre-Beinier $^{4}$. \\ Catherine Aquino ${ }^{1} \cdot$ Bart Vrugt $^{5} \cdot{\text { Marc de } \text { Perrot }^{2} \cdot \text { Beat Schwaller }}^{3} \cdot$ Emanuela Felley-Bosco $^{6}$
}

Received: 1 September 2017 / Revised: 11 December 2017 / Accepted: 30 December 2017 / Published online: 6 March 2018

(c) The Author(s) 2018. This article is published with open access

\begin{abstract}
Chronic exposure to intraperitoneal asbestos triggered a marked response in the mesothelium well before tumor development. Macrophages, mesothelial precursor cells, cytokines, and growth factors accumulated in the peritoneal lavage. Transcriptome profiling revealed YAP/TAZ activation in inflamed mesothelium with further activation in tumors, paralleled by increased levels of cells with nuclear YAP/TAZ. Argl was one of the highest upregulated genes in inflamed tissue and tumor. Inflamed tissue showed increased levels of single-nucleotide variations, with an RNA-editing signature, which were even higher in the tumor samples. Subcutaneous injection of asbestos-treated, but tumor-free mice with syngeneic mesothelioma tumor cells resulted in a significantly higher incidence of tumor growth when compared to naïve mice supporting the role of the environment in tumor progression.
\end{abstract}

These authors contributed equally: Hubert Rehrauer, Licun Wu.

Electronic supplementary material The online version of this article (https://doi.org/10.1038/s41388-018-0153-z) contains supplementary material, which is available to authorized users.

Emanuela Felley-Bosco

emanuela.felley-bosco@usz.ch

1 Functional Genomics Center Zurich, ETH Zurich and University of Zurich, 8057 Zurich, Switzerland

2 Latner Thoracic Surgery Research Laboratories, Division of Thoracic Surgery, Toronto General Hospital University Health Network, University of Toronto, Toronto, ON, Canada

3 Department of Medicine, Unit of Anatomy, University of Fribourg, Route Albert-Gockel 1, CH-1700 Fribourg, Switzerland

4 Department of Thoracic Surgery, University Hospitals of Geneva, Geneva, Switzerland

5 Institute of Surgical Pathology, University Hospital Zurich, Zurich, Switzerland

6 Laboratory of Molecular Oncology, Lungen- und Thoraxonkologie Zentrum, University Hospital Zürich, Sternwartstrasse 14, 8091 Zurich, Switzerland

\section{Introduction}

The association of exposure to asbestos with development of mesothelioma has been demonstrated in the seminal experimental work of Wagner in the 1960s [1]. In 1987, Kane and co-workers [2] observed that already a single dose of asbestos fibers damages the mesothelium tissue and stimulates regeneration with the additional recruitment of macrophages to the site of damage and were the first to propose that persistent tissue injury leads to an inflammatory and regenerative response, which subsequently paves the way to mesothelioma development.

Tumor development greatly depends on the evasion from the immune surveillance. Tumor cells escaping the immune defense is enhanced by the induction of an immunosuppressive tumor microenvironment [3]. For example, the differentiation and activation of antigen-presenting dendritic cells, which are the key initiators of the adaptive immune responses [4], are inhibited by signals, e.g., vascular endothelial growth factor (VEGF), present in the tumor microenvironment [5]. Tumor-associated macrophages polarized to a "M2" state [6] as well as a heterogeneous population of myeloid-derived suppressor cells, are potent suppressors of antitumor immunity [7]. Others and we have previously observed that blockade of immunosuppressive signals enhances immunity against mesothelioma [8-12]. 
A

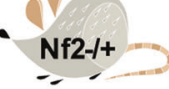

21 wks $\quad 12$ wks

6-8wks old C57/BI6

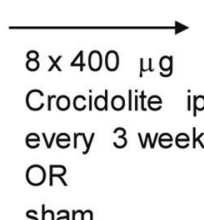

$\rightarrow$

33 wks after first exposure

sham

Mesothelium/mesothelioma

Peritoneal lavage

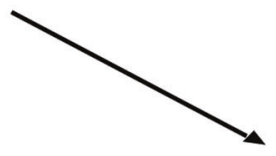

Immune cell population mesothelial precursor

Spleen/pancreas/fat/liver Cytokines/chemokines Mesothelium/mesothelioma Pathology, IHC

Variation of gene expression

Peritoneal lavage
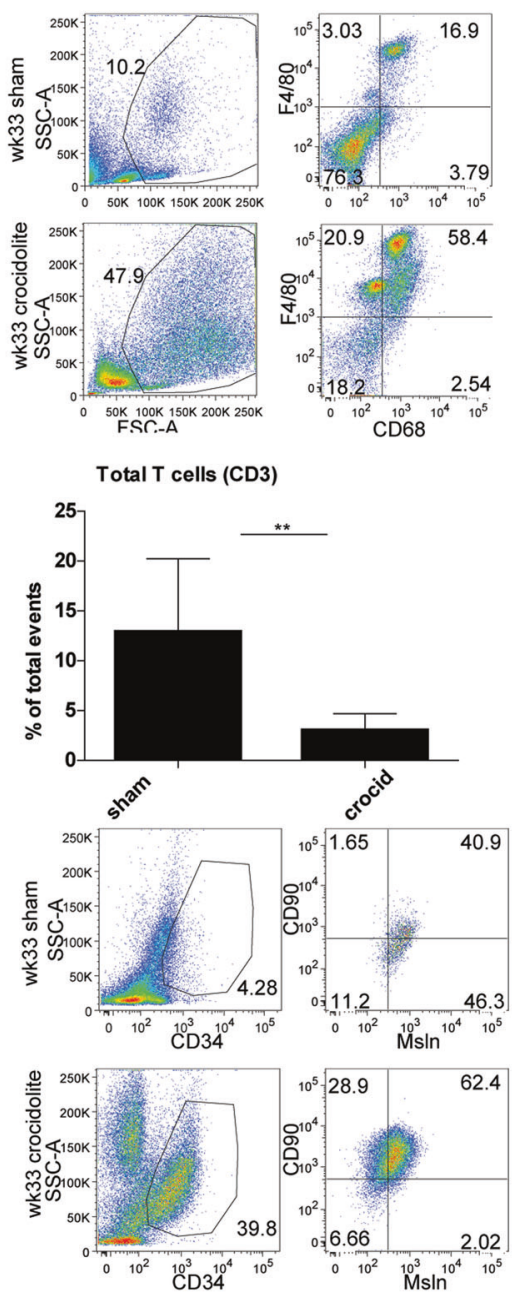
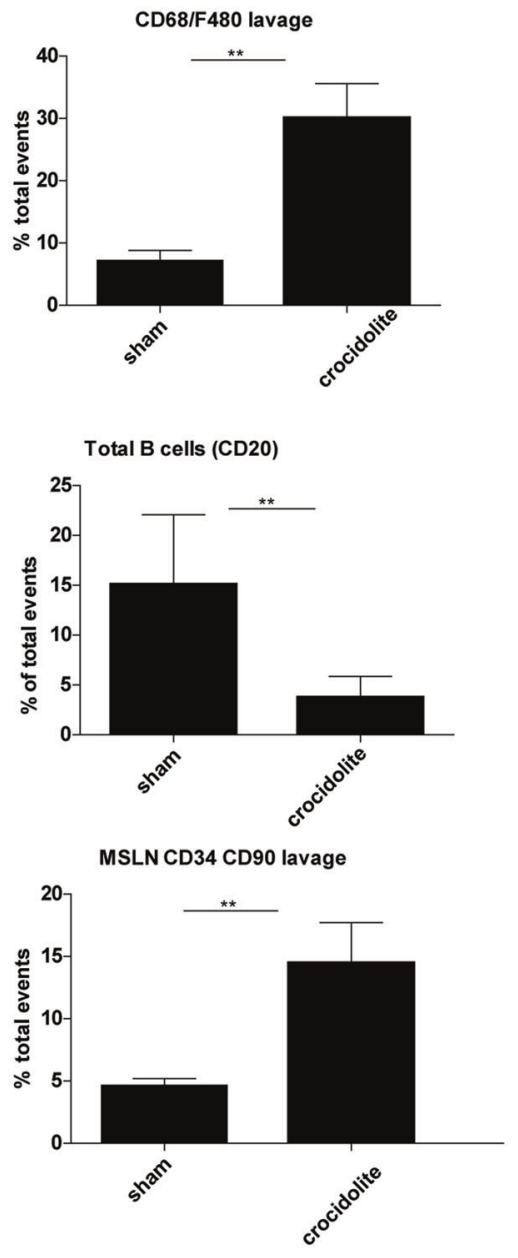

Spleen
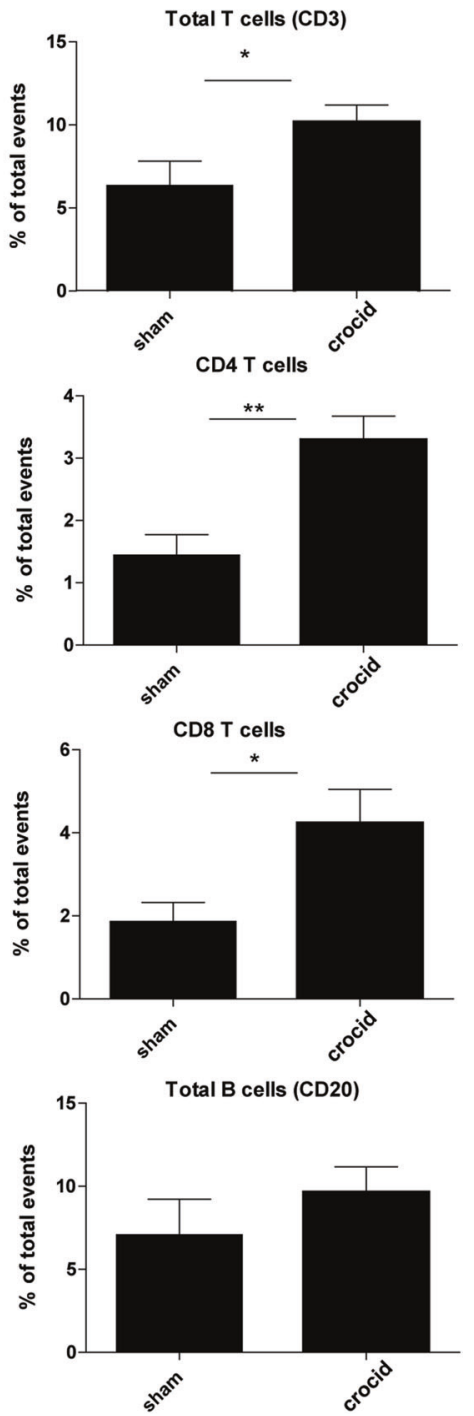

This study assesses the loss of homeostasis in the mesothelial environment during tumor development after exposure to asbestos. Since mesothelioma development after intraperitoneal exposure to asbestos has been widely accepted as a bona fide surrogate to investigate mesothelium-dependent reaction, we used this model to 
Fig. 1 Exposure to asbestos alters the profile of cell populations in peritoneal lavage. a Experimental scheme: 6-8-week-old C57Bl/6J mice were exposed to crocidolite i.p. ( $400 \mu \mathrm{g} /$ mouse) every 3 weeks with in total eight treatments. Thirty-three weeks after initial exposure to crocidolite mice were sacrificed to collect peritoneal lavage, blood, and tissues. Tumor-bearing mice were sacrificed to collect tumor tissue. b The lavage from crocidolite-exposed mice shows higher proportions of macrophages and mesothelial precursor populations as compared to sham-exposed mice. Flow-cytometry analysis of samples is shown in the left panel. A significant decrease in the total number of $\mathrm{T}$ and $\mathrm{B}$ cells was observed in the peritoneal lavage 12 weeks after last exposure to crocidolite. $\mathbf{c}$ The proportion of $\mathrm{T}$ cells was significantly increased in the spleen of asbestos-exposed mice. No difference for B cells was observed in the spleen. $N=6-8$ mice. Mean \pm SE. $* p<0.05$, $* * p<0.01$, Mann-Whitney test

investigate in-depth how perturbation of homeostatic control leads to tumor development. Nf $2+/-$ mice on a $\mathrm{C} 57 \mathrm{Bl} /$ $6 \mathrm{~J}$ genetic background were used for several reasons including the observation that tumor that develop in Nf2 +/- mice exposed to asbestos show common genomic alterations with human mesothelioma and loss of NF2 function has a driver role in mesothelioma development [13-16], and C57Bl/6J mice being widely used in functional studies.

\section{Results}

\section{Exposure to asbestos alters the profile of cell populations and signaling molecules in the peritoneal cavity in non-tumor bearing mice}

C57B1/6J Nf2+/- mice were exposed eight times to crocidolite (blue asbestos) every 3 weeks then were sacrificed 33 weeks after first crocidolite exposure in order to have the possibility to investigate pre-cancer and cancer stages (Fig. 1a). In mesothelioma-free mice, the population of CD68/ F480 macrophages in the peritoneal lavage was five-fold higher compared to sham-exposed mice (Fig. 1b). Both, the numbers of $\mathrm{T}$ and $\mathrm{B}$ cells (Fig. 1b) in the peritoneal lavage of crocidolite-treated mice were significantly decreased.

Besides macrophage recruitment after tissue damage, free-floating mesothelial-like cells were shown to be incorporated into peritoneal wound surfaces and to contribute to the regeneration of the damaged mesothelium [17]. This population is characterized as mesothelin ${ }^{+}$(Msln ${ }^{+}$)-bone marrow-derived progenitor cells [18]. During embryonic development, a mesothelial precursor population has been identified as $\mathrm{Ms}^{+} \mathrm{CD} 105^{\text {low }}, \mathrm{CD} 90^{\text {high }}, \mathrm{CD} 44^{\text {low }}$, and CD34 ${ }^{\text {high }}$ [19]. Accordingly, we observed that CD90 ${ }^{+} \mathrm{CD} 34{ }^{+} \mathrm{Msln}^{+}$cells paralleled the CD68/F480 cell profile (Fig. 1b). In the spleen a significant increase of $\mathrm{T}$ cells, both CD4 and CD8, was observed (Fig. 1c).
In order to explore mechanisms putatively involved in the observed changes, the content of different inflammatory cytokines (IL-6, IL-10, IFN $\gamma$ ), myeloid chemoattractant chemokines (CCL-2, CCL5, CXCL1), and growth factors modulating the differentiation of myeloid cells (G-CSF, GM-CSF) or vessel growth (VEGF), was measured in the peritoneal lavage (Fig. 2). Levels were increased in crocidolite-exposed mice paralleling the profile change observed for the CD68/F480 and mesothelial precursor cell populations. A strong correlation was observed between CCL2 and IL-6 levels ( $r=0.7, p<0.0001)$ consistent with the known reciprocal regulation of these two cytokines [20].

\section{RNA-seq transcriptome profiling}

Tumors showing spindled morphology and benign mesothelial proliferations cells that had grown in asbestosexposed mice stained positive for podoplanin, WT-1, mesothelin, vimentin, and cytokeratin (Supplementary Figure 1).

We collected scraped mesothelium (Fig. 3a) and performed RNA-seq to identify gene expression changes during mesotheliomagenesis. We analyzed three groups by RNA-seq: sham, age-matched crocidolite-exposed, and agematched crocidolite-exposed with observable tumors. Among those groups we performed differential expression analysis between crocidolite-exposed and sham, and detected 5976 differentially expressed genes $(p<0.01$, false-discovery-rate $($ FDR $<0.022)$. Additionally we assessed the expression differences between crocidolite exposed with tumors and crocidolite exposed, and identified 8416 genes $(p<0.01$, FDR $<0.017)$. In Fig. $3 b$, we show a heatmap of the significant genes where we applied an additional fold-change threshold of higher than two-fold (2316 genes up, 84 genes down when comparing crocidolite-exposed and sham). The crocidolite response is dominated by an upregulation of genes. It is interesting to note that among the 2316 genes with a positive response, 1989 have an even higher average expression in the crocidolite-with-tumor samples as compared to the crocidolite samples and only 327 genes have a lower average expression. However, this asymmetry is not generally true, when looking at all genes significantly changed between crocidolite with tumors and crocidolite without tumors. We find 3014 genes with more than two-fold upregulation and 3008 genes with more than two-fold downregulation. A total of 1234 genes of these two upregulated gene sets were overlapping, as shown in the Venn diagram (Fig. 3c). The commonly upregulated 1234 genes represent $53 \%$ of the upregulated genes in the crocidolite-exposed tissue vs. sham-exposed pool and $41 \%$ in the crocidolite-exposed tumor vs. crocidolite-inflamed tissue pool (Fig. 3c). A 
Fig. 2 Exposure to asbestos alters the profile of signaling molecules in the peritoneal lavage. 6-8-week-old C57Bl/6J mice were exposed to crocidolite i.p. (400 $\mu \mathrm{g} / \mathrm{mouse})$ every 3 weeks for eight rounds. Thirtythree weeks after initial exposure to crocidolite mice were sacrificed to collect peritoneal lavage to determine the levels of several cytokines, growth factors, and chemokines. All of them were more abundant in the lavage from crocidolite-exposed mice. $N=6-8$ mice. Mean \pm SE. $* * p<0.01$, Mann-Whitney test
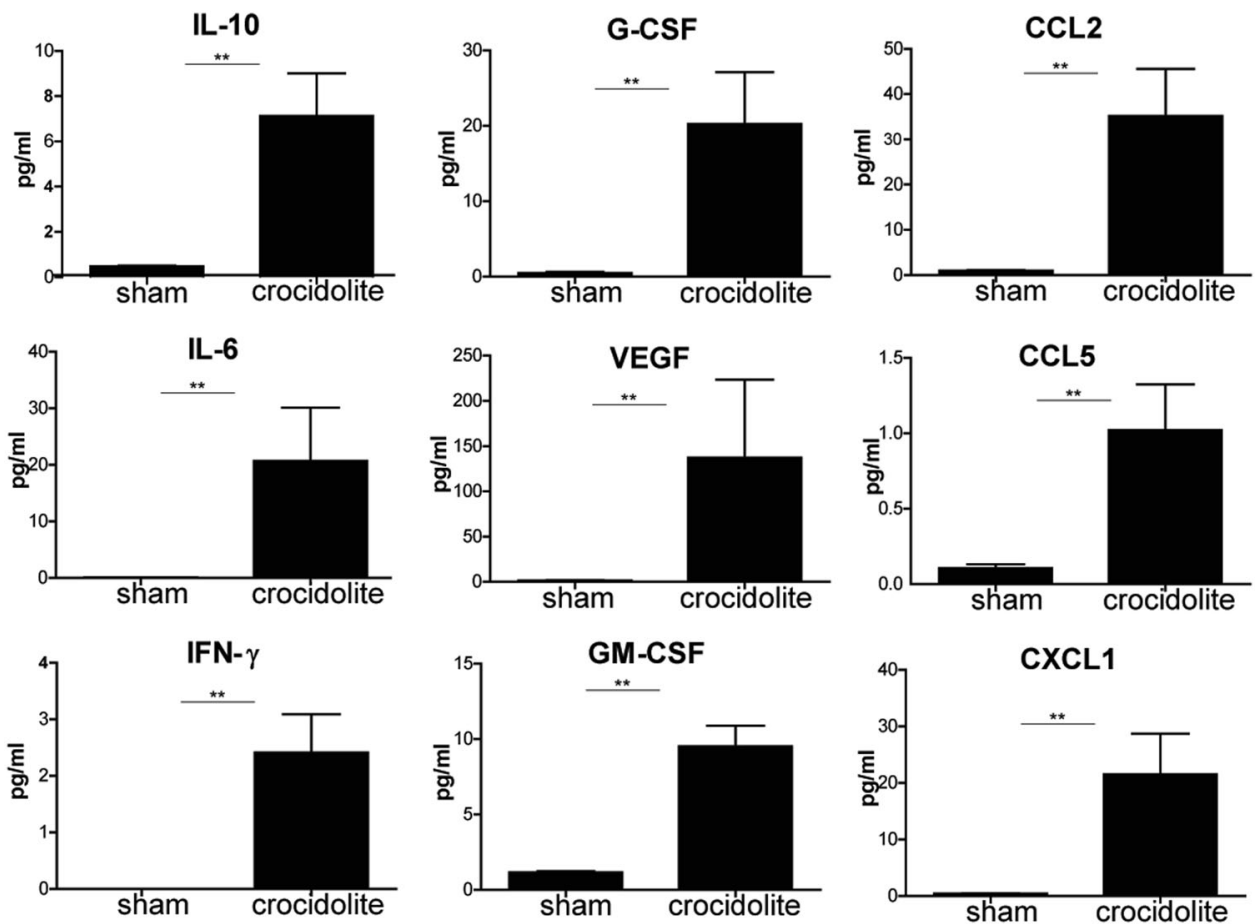

functional analysis of these different responding gene groups is discussed below.

We further looked at the number and type of base changes in the RNA-seq data. In Fig. 3d, we show the mutational load as determined from the strand-specific RNA-seq read alignments. The crocidolite-exposed mice show higher number of mutations as compared to sham treated. After tumorigenesis, the number of mutations was even further increased. Figure $3 \mathrm{~d}$ shows that there is one crocidolite non-tumor sample with a very high number of mutations. This outlier sample has been obtained from a mouse with no visible tumor. In gene expression analysis its profile was intermediate between tumor and crocidolite without tumor samples, and histological examination by the pathologist has revealed the presence of some neoplastic cells. Because only one sample exhibited this characteristic, we have excluded it from further expression analysis but included it in the base-change analysis. Excluding it from the base-change analysis does not substantially alter the results. When looking closer at the type of mutations, we observed a significant increase of A to G mutations between crocidolite and sham-treated samples. This increase is significant in terms of absolute counts $(p=0.005)$ and in terms of the relative fractions of the A to $\mathrm{G}$ mutations of the total mutations $(p=0.00031)$ (Fig. 3e). The $A$ to $G$ alterations were increased while the $T$ to $C$ alterations were not, which identifies them as RNA-editing events. Actually, none of the other mutation types showed a significant increase neither in absolute nor in relative terms. Even more, Fig. 3f shows that the fraction of A to $G$ alterations that overlaps with known A to I sites also increases $(p=0.0012)$. We hypothesize that they are the result of hydrolytic deamination of adenosine downstream of Adar activity [21] (I is detected as G in RNA-seq). This is consistent with a significant 3.9-fold increase of Adar expression in inflamed tissue compared to sham ( $p=$ $5.35 \mathrm{E}-34, \quad \mathrm{FDR}=7.87 \mathrm{E}-32$ ) and more than two-fold increase in tumors compared to inflamed tissues $(p=$ $2.56 \mathrm{E}-12, \quad \mathrm{FDR}=1.86 \mathrm{E}-11)$. Intriguingly Adarb1 showed a significant more than two-fold increase in tumors compared to inflamed tissues $(p=2.56 \mathrm{E}-12, \mathrm{FDR}=1.86 \mathrm{E}$ -11 ), but its expression was not significantly changed between sham and inflamed tissue. Analysis of TCGA mesothelioma data revealed that high expression of $A D A R B 1$ is associated with worst overall survival (Supplementary Figure 2) supporting the idea that RNA editing is relevant in mesothelioma as it is in other cancers. In order to document deeper this aspect, we first identified a candidate RNA locus, AZIN1, in our list of edited sites, which had already been shown to contribute to tumor growth [22]. Fisher's exact test indicated that AZIN1 editing is significantly $(p=0.010)$ enriched in samples from asbestosexposed animals (Supplementary Figure 3A). We then used two different mesothelioma cell lines, SPC111 and NCIH226, and documented that they express both, ADAR and ADARB1 (Supplementary Figure 3B). Both isoforms of ADAR are expressed, p110 and p150, but p110 is more abundant. ADAR expression is higher in SPC111 cells compared to NCI-H226 cells while ADARB1 expression is very low in SPC111 cells but high in NCI-H226 cells, 
A

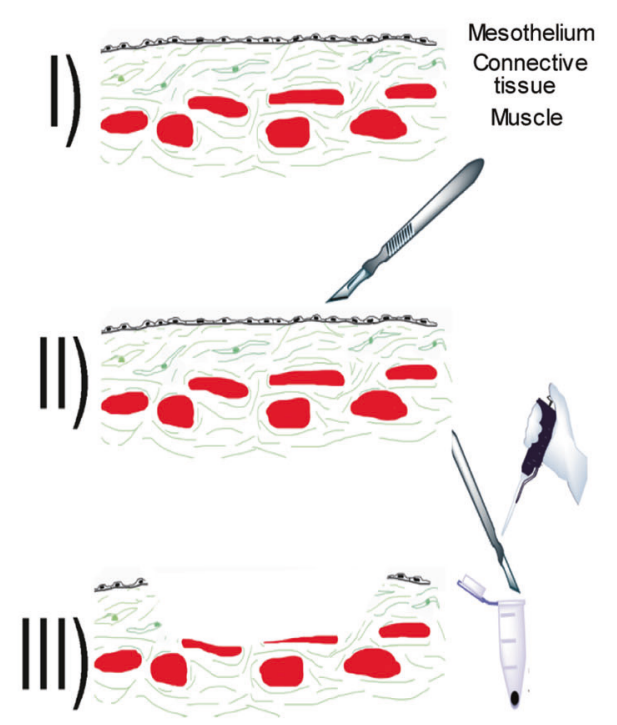

C

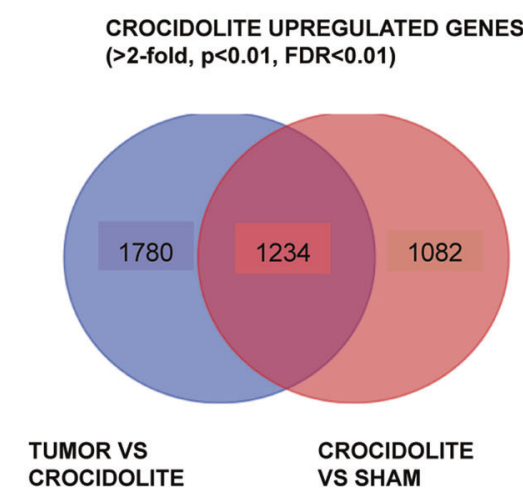

E

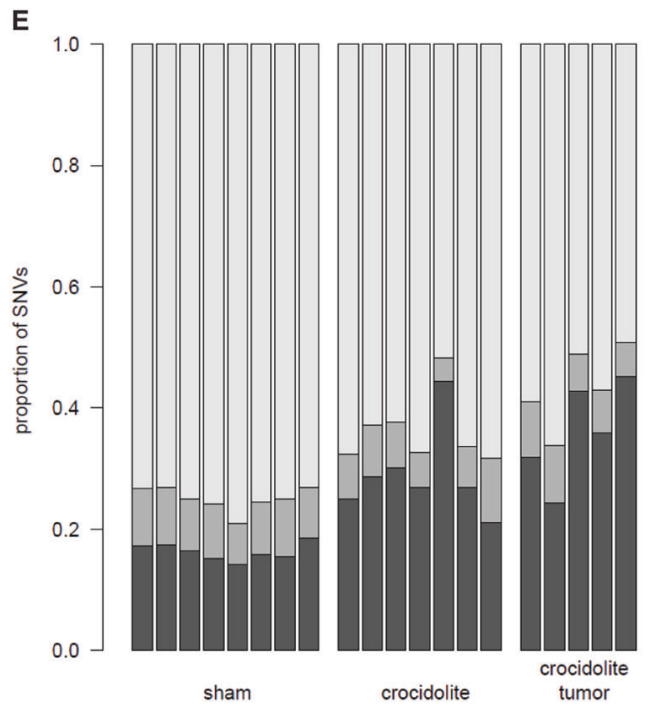

demonstrating that both enzymes are expressed in mesothelioma. We then used a recently developed sensitive RNA editing site-specific quantitative RT_PCR [23] to document
B
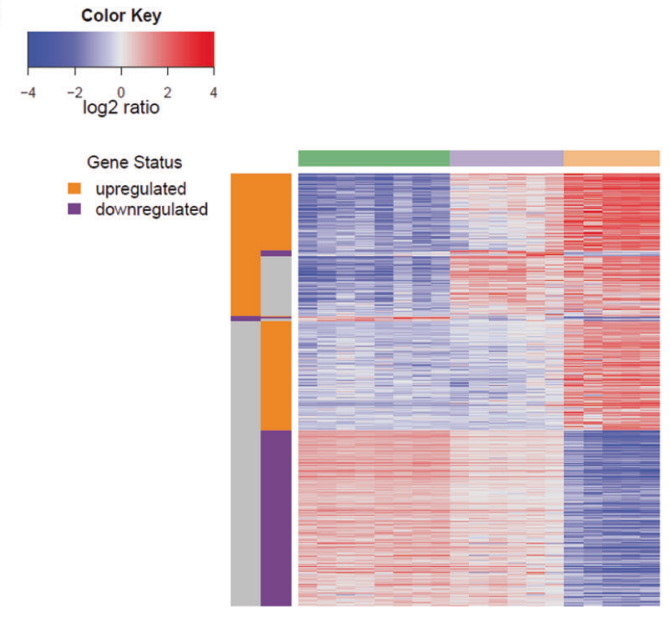

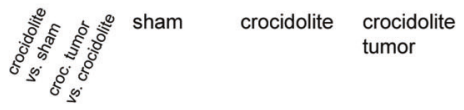

D

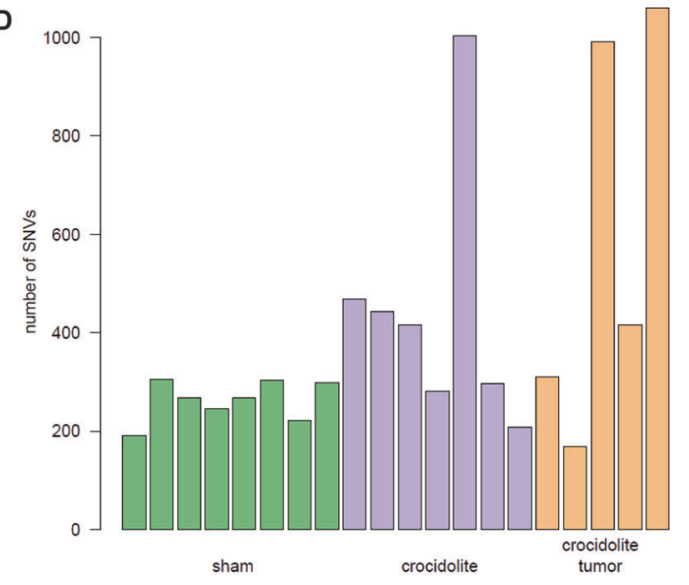

$\mathbf{F}$

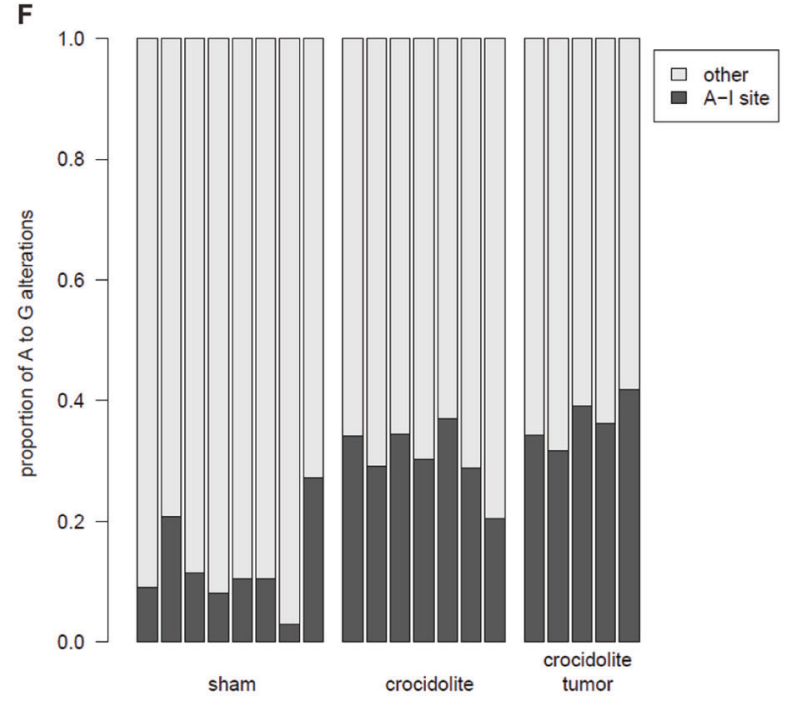

that silencing ADAR and ADARB1 (Supplementary Figure 3B) results in decreased AZIN1 RNA editing (Supplementary Figure $3 \mathrm{C}$ ). Therefore, both enzymes are active 
Fig. 3 Transcriptome profiles reveal higher expression for thousands of genes and an increase of RNA editing events. a Mesothelial tissue collection by exposure of parietal mesothelium and scraping the surface with a scalpel. b Heatmap of differentially expressed genes in the two comparisons crocidolite vs. sham and crocidolite tumors vs. crocidolite. The color bars at the left indicate upregulation (orange) and downregulation (violet). The crocidolite vs. sham comparison is dominated by genes upregulated in the crocidolite condition. c Overlap of the differentially expressed genes (two-fold change, $p<0.01$ ) in both comparisons visualized as a Venn diagram. There is a substantial overlap that originates from the fact that about $40 \%$ of the genes that are upregulated in the crocidolite condition, show an even higher expression in the crocidolite tumor tissue. $\mathbf{d}$ Number of detected single nucleotide variations (SNV) in RNA-seq reads. e An increase of A to $G$ transitions is the major cause of the increased number of SNVs in crocidolite-exposed tissues. Please note the reads are strand specific and the reverse complement transition ( $\mathrm{T}$ to $\mathrm{C}$ ) is not increased. $\mathbf{f}$ The proportion of A to $\mathrm{G}$ mutations that coincide with known A to I RNAediting sites increases also in the crocidolite-exposed tissues

in mesothelioma cells proving that they contribute to the RNA editing signature.

\section{Functional analysis of differentially expressed genes}

Genes known to be upregulated during mesothelioma development, such as Osteopontin (Spp1) and mesothelin $(M s l n)$, were increased validating our approach (Fig. 4a). As expected the expression of $N f 2$ and Bapl, tumor suppressors frequently mutated in mesothelioma [24-27] were significantly decreased during mesothelioma development (Fig. 4b). Relative quantification of gene copy number [28] was used on genomic DNA from a cell line established from one tumor (RN5) compared to non-tumor cells. We considered it as valid surrogate to examine Bapl and $N f 2$ copy number changes because data could be compared to protein levels. We observed that loss of one allele in Bapl gene was accompanied by decreased protein levels, while loss of the second $N f 2$ allele abolished Nf2 protein expression (Supplementary Figure 4A and B). Nf2 is an upstream regulator of the Hippo signaling cascade [29], which prevents nuclear YAP/TAZ localization and activation of transcription enhancers activation domain (TEAD) family members [30]. Accordingly, we observed a progressive increase in nuclear YAP localization in parallel to an increase in the proliferation marker Ki-67 in benign growth and tumor tissue from crocidolite-exposed mice (Fig. 4c).

Gene set enrichment analysis [31] of differentially expressed genes indicated that the most significant pathway activated in inflamed tissue compared to sham was activation of interferon- $\gamma$ (Supplementary Table 1, $p=3.89 \mathrm{E}$ -79), while enrichment in epithelial-mesenchymal transition (EMT) markers in tumors was the most significant pathway in tumors compared to crocidolite-exposed inflamed tissue (Supplementary Table 2, $p=8.92 \mathrm{E}-81$ ). Many of these genes were downstream of p53 activation, replication stress, or YAP activation (Supplementary Table 3 ). The number of upregulated genes in the pool of YAP activation pathway signature genes was almost doubled between tumors and inflamed tissue (Fig. 5a). One of these genes, Ctgf, showed increased expression in tumors, but not in inflamed tissues (Fig. 5b), consistent with Ctgf expression being synergistically enhanced by TGF $\beta$ [32] and enrichment of EMT markers in tumors.

\section{Activation of developmental genes is predominant in tumors while both inflamed mesothelial tissue and tumor contain Arg1-positive cells}

To further explore unique and common genes, we used Gene Ontology Term Finder (http://go.princeton.edu/cgibin/GOTermFinder) to find associated GO terms, and Reduce and Visualize Gene Ontology (REVIGO) [33] to group terms in a two-dimensional space based on semantic similarity (Fig. 5c). While biological processes upregulated in crocidolite-exposed tissues included cytokine production, inflammatory response and leukocyte-mediated cytotoxicity, cell cycle and wound healing were upregulated in both, crocidolite-exposed non-tumor and tumor tissues. In the latter, Gene Ontology (GO) categories linked several genes to developmental processes. Figure $5 \mathrm{~d}$ shows a heatmap for selected genes belonging to categories related to development. Ten of the identified 38 genes are part of the Hedgehog pathway and Ephrin/Semaphorin pathways including Gasl, Cdon, Gli2, Smo, Sufu; Sema4f, Ephb2, Sema3f, Sema3c, and Efnbl, consistent with TCGA data showing that these two pathways are part of the top ten pathways deregulated in human mesothelioma [34]. The Hedgehog signaling pathway is essential during embryonic mesothelial development [35] and is inactive in most adult tissues, but increased Hedgehog signaling is observed in mesothelioma tumors [36], especially in the sarcomatoid histotype [27]. Five genes ( $F z d 8, F z d 2$, Dvl2, Porcn, and Rspol) are part of the Wnt pathway and eight genes are part of homeobox families: five (HoxaA1, HoxaA2, HoxA3, HoxB2, and HoxB3) from the Hox family, which defines the morphology of a specific body segment during embryonic patterning and participates in tissue regeneration. The rest of the genes are either part of the BMP/Tgf beta pathway (Bmpl, Bmp4, Grem1, Chor, Cdhl1, and Tgfi), genes implicated in kidney development (four genes) or in the Notch pathway (two genes). Few other genes have already been associated with human mesothelioma such as Lif [37]. Analysis of pleural mesothelioma compared to matched normal tissue data [38] revealed that expression of these genes is also increased in human tumors compared to normal tissue, indicating that activation of these developmental pathways is not species specific. Interestingly, one of the genes with the strongest upregulation $(p=2.84 \mathrm{E}-12$, FDR 
Fig. 4 Progressive deregulation of the Hippo pathway during mesothelioma development. a Increased expression of Spp1 and $M \sin$ mesothelioma markers in crocidolite-exposed mice validates our approach. qPCR for Sppl and Msln expression was performed in sham, crocidolite-exposed mice without malignant tumor and tumors. Mean \pm SE. $N=5-8$ mice, $* p<0.05$, Mann-Whitney test. b Nf2 and Bapl tumor suppressors were significantly decreased during mesothelioma development. Gene expression of $N f 2$ and $B A P 1$ were analyzed as in a. ${ }^{*} p<0.05$,

Mann-Whitney test. c Nuclear YAP and ki67 expression in crocidolite-exposed mice. Immunoreactivity for Ki67 and YAP observed in benign growth and in tumors in crocidoliteexposed mice
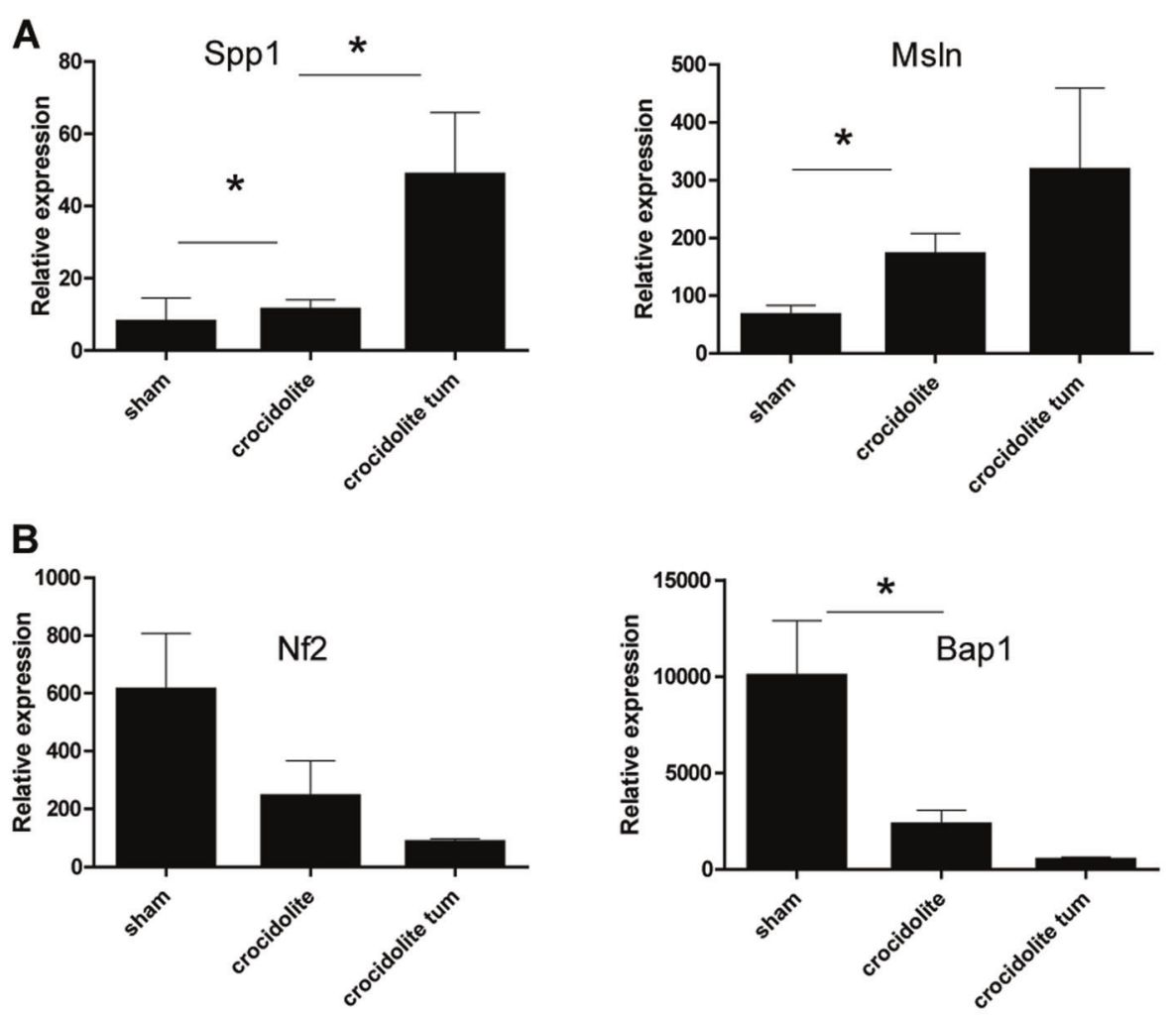

\section{C}
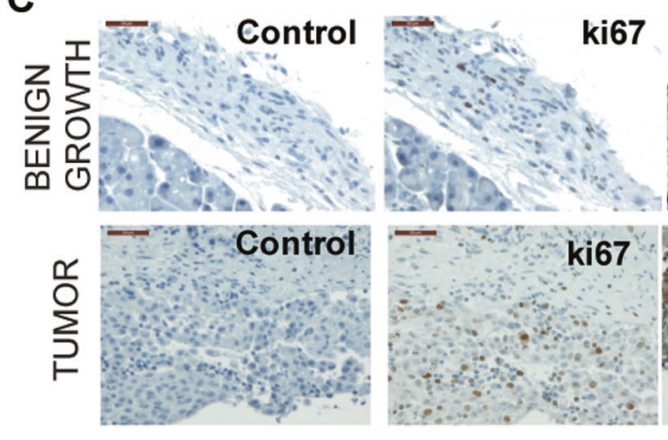

ki67

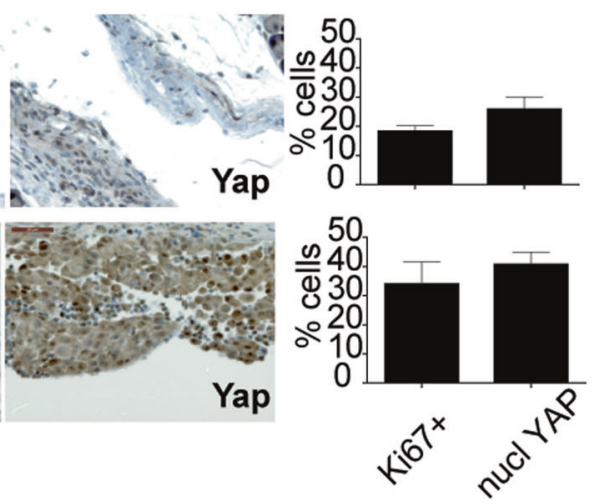

$=2.05 \mathrm{E}-11)$ in tumors compared with crocidolite-exposed tissue was Grem1, a secreted bone morphogenetic protein (BMP) antagonist, which has been recently described to promote EMT in mesothelioma [39] (Fig. 5e).

Among the genes with the highest upregulation in crocidolite-exposed tissues vs. sham-exposed, and with further upregulation in crocidolite-induced tumor tissue compared to crocidolite-exposed tissue was Argl ( $p=$ $6.83 \mathrm{E}-65, \mathrm{FDR}=2.98 \mathrm{E}-61$, Fig. 6a). Arginase 1 is one of the two enzymes, which hydrolyzes L-Arg to urea and Lornithine, the latter being the main substrate for the production of polyamines that are required for cell cycle progression. Arginase 1 expression was also confirmed in crocidolite-exposed tissue and tumors by immunohistochemistry (Fig. 6a). The expression of Arginase 1 is considered to be the hallmark of the "M2"-state macrophage population, which can cause T-cell anergy [40], however it was expressed also in some reactive mesothelial cells which were not stained with the macrophage marker F4/80 (Supplementary Figure 5). Interestingly a gene signature implicated in the activation of tissue macrophage self-renewal and embryonic stem cells [41], was upregulated in crocidolite-exposed tissues and tumors (Fig. 6b), supporting the hypothesis of environment-driven stimulation of pluripotency potential. This observation was reinforced by unbiased oPOSSUM analysis (http://opossum.cisreg.ca/cgibin/oPOSSUM3/opossum_mouse_tca) indicating that Klf4 ranked first among the transcription factors with overrepresented binding sites in genes that were upregulated in asbestos-induced inflamed tissue $(Z$-score $=46.47)$. 
A

YAP TARGETS $(n=138)$

- crocidolite infl only

- tum \& crocidolite infl

- tum only

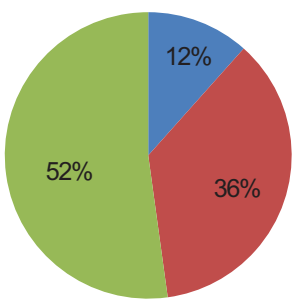

B

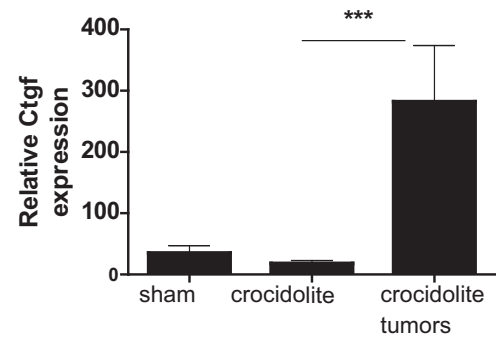

D

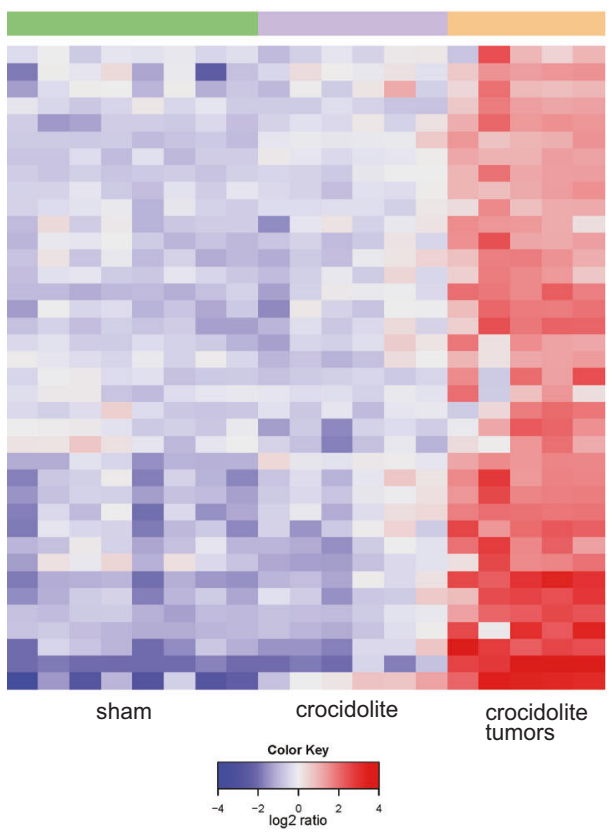

E

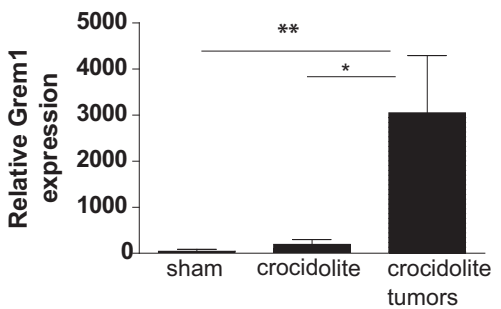

C

BP UP CROCIDOLITE $(n=1082)$

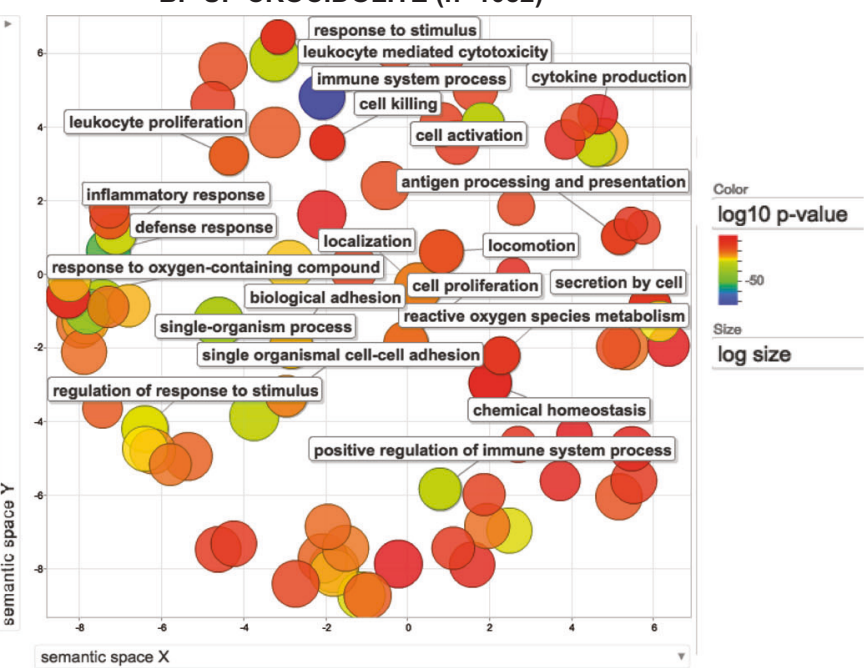

BP UP COMMON ( $n=1234)$

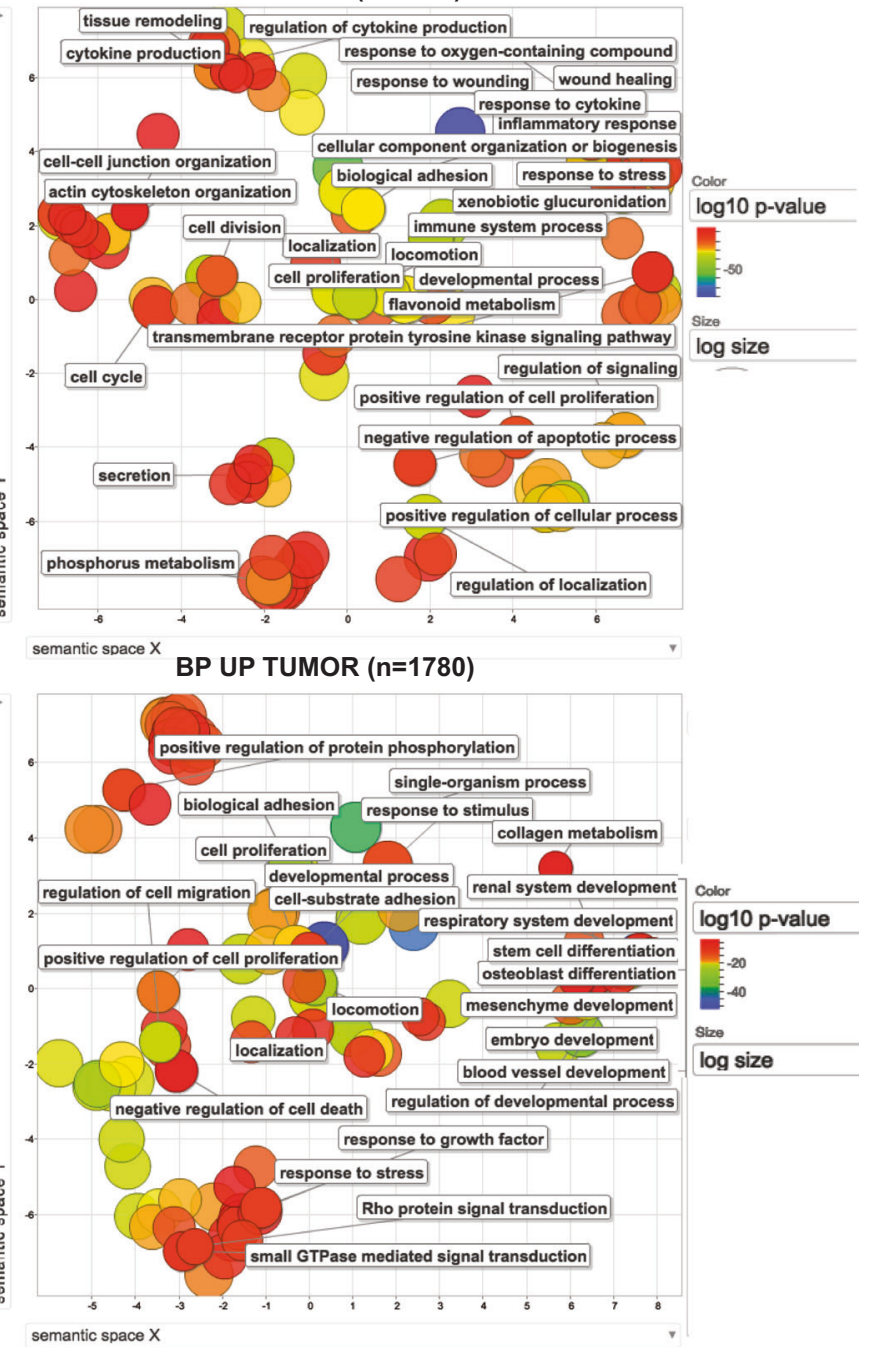


4 Fig. 5 Activation of developmental pathways in mesotheliomagenesis. a Pie chart of significantly increased YAP1 target genes distribution in inflamed tissues vs. tumor. The detailed list of genes is listed in Supplementary Table 3. b q-PCR of Ctgf expression was performed in sham, crocidolite-exposed mice without malignant tumor and tumors. Mean \pm SE. $N=5-8$ mice. $* * * p<0.005$, Mann-Whitney test. c The list of genes from each of the three categories of the Venn diagram of Fig. 3 were subjected to GO analysis to identify enriched GO terms for biological processes (BP). The results are shown as REVIGO scatter plots in which similar terms are grouped in a two-dimensional space based on semantic similarity. Each circle indicates a specific GO term and circle sizes are indicative of how many genes are included in each term. Colors indicate the level of significance of enrichment of the GO term. d A curated heatmap was generated for gene sets belonging to categories related to development and that were enriched in tumors. Red represents increased expression. e Overexpression of Greml in tumors was verified by q-PCR. Mean \pm SE. $N=5-8$ mice. ${ }^{*} p<0.05$, $* * p<0.01$, Mann-Whitney test

Furthermore, curated heatmaps confirmed upregulation of molecules associated with the "M2"-polarized macrophage such as Csfl, Csfrl, and Cd163 (Supplementary Figure 6). Altogether, these observations suggest that the increase in the macrophage population resulting from crocidolite exposure is mostly due to "M2"-polarized macrophages.

Expression levels of chemokines such as $\mathrm{Ccl} 2, \mathrm{Ccl} 5$, and Cxcl- 1 was increased in non-tumor tissue from crocidoliteexposed mice (Supplementary Figure 7) consistent with the observed increase of these signaling molecules in the peritoneal lavage, and even higher levels were measured in tumor tissue. In addition, we observed upregulation of other chemokine receptors such as Ccrl, Ccr3, Ccr5, Cxcr3, Cxcr4, Cxcr6, Cx3crl, and their ligands (Supplementary Figure 7). As expected, IL-1 $\beta$ and TNF $\alpha$ were significantly upregulated $(p=3.54 \mathrm{E}-13, \mathrm{FDR}=7.89 \mathrm{E}-12$ and $p=$ $1.87 \mathrm{E}-18, \mathrm{FDR}=8.17 \mathrm{E}-17$, respectively) in mesothelium scraped from asbestos-exposed mice, compared to mesothelium from sham mice.

\section{Inflamed environment favors tumor growth}

Finally, in order to investigate whether inflammation observed after asbestos exposure in non-tumor bearing mice would affect tumor growth, tumor-free animals 49 weeks after the first asbestos exposure were challenged with s.c. flank injection of a dose of RN5 syngeneic cells $\left(1 \times 10^{6}\right)$ expected to give rise to tumors only in a fraction of agematched recipients naïve mice. One mouse exposed to asbestos developed a peritoneal mesothelioma and all the other asbestos-exposed mice developed a s.c. tumor within 50 days while two naïve mice were still tumor-free 150 days after injection of RN5 cells (Fig. 6c), supporting the concept of mesothelial environment changes favoring tumor growth. However, no obvious differences in tumor morphology were noticed (Fig. 6d).

\section{Discussion}

In this study we provide strong evidence that mesothelioma might be caused by conditions that trigger chronic inflammation where activation of YAP/TAZ signaling, RNA editing, and a tumor-promoting environment appear prior to tumor development. The RNA editing signature downstream ADAR activity is suggested by A to $G$ mutations at known A to I sites and is consistent with its increased expression, possibly due to interferon signaling [42]. Decreased expression of ADARB1 has been observed upon YAP silencing in mesothelioma cells, which resulted in decreased cell growth [43] providing a possible mechanism behind the TCGA data associating high ADARBI expression with worst overall survival. RNA editing by ADAR is the most prevalent type of RNA editing and occurs mostly in non-coding regions where inverted repeated sequences are likely to form dsRNA structures, which functions as substrate. It has recently attracted attention as cancer driver for its role in cancer stem cell maintenance, possibly linked also to reduced production of mature miRNA due the impairment of their processing by Drosha after editing of hairpin structures in primitive miRNA [21, 44]. Although we could not evaluate miRNA abundance or mutations due to the method used to extract RNA, it is worth noting that YAP activation has been shown to decrease the activity of Drosha [45], therefore RNA editing and YAP/TAZ activation may converge on profound modification of mature miRNA. The progressive activation of YAP/TAZ signaling is possibly associated with extra-cellular matrix (ECM) remodeling since several GO terms induced by crocidolite are associated with this process. Indeed, a signatures revealing activation of YAP/TAZ signaling was significantly associated to growth on high stiffness ECM [46]. YAP/TAZ signaling is functionally required for differentiation of mesenchymal stem cells induced by ECM stiffness and nuclear YAP/TAZ localization has been associated with response to increased ECM stiffness in several tissues $[47,48]$. The progressive deregulation of the Hippo pathway associated with YAP/TAZ activation is consistent with previous published results on the role of NF2 in human mesothelioma development [16], stressing the importance of this signaling pathway in mesothelioma growth. Interestingly, some differences in the profile of YAP/TAZ targets in inflamed tissues vs. tumor suggest the existence of modulation of YAP/TAZ activation [49] including matrix remodeling in inflamed tissue or EMT cues in tumors. This would be consistent with the observed enrichment of EMT signature, the overexpression of Greml in mice tumors and Greml upregulation in the sarcomatoid histotype of human mesothelioma [27]. It is also in agreement with the EMT signature associated with worst 
A

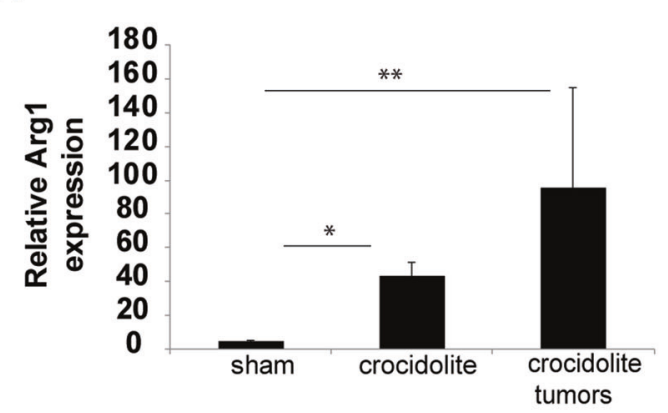

B

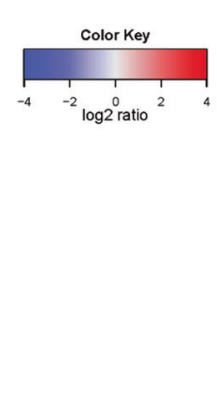

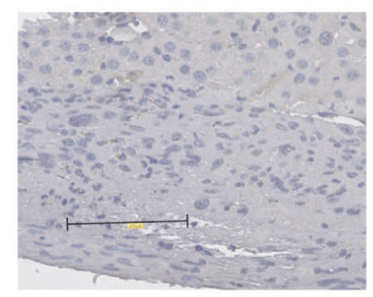

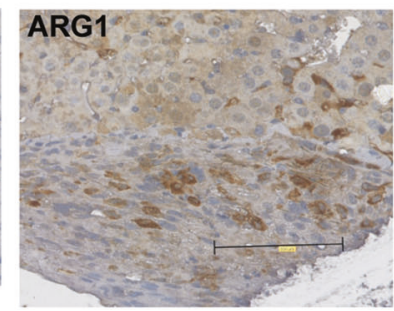

C

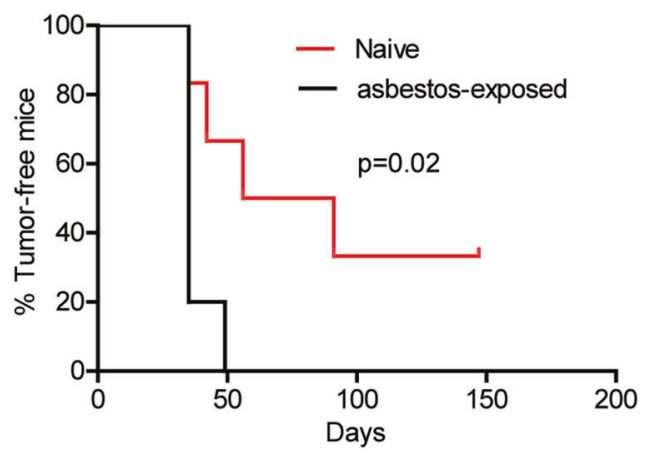

Fig. 6 Increase in Arg1-positive cells in both inflamed mesothelial and tumor tissues. a Relative expression of Argl was verified by q-PCR. Argl was highly increased in crocidolite-exposed tissue and expression was maintained in tumors Mean \pm SE. $N=5-8$ mice. ${ }^{*} p<0.05$, $* * p<0.01$, Mann-Whitney test compared to sham. Arginase 1 (Arg1)positive cells were detected in the tumors. b Marker genes for self- renewing macrophages [41] shows increased expression in crocidoliteexposed tissues and tumors. c Kaplan-Meier graph of tumor-free mice survival after challenging with RN5 mesothelioma cells $\left(1 \times 10^{6}\right)$ mice exposed to asbestos that had not developed a tumor until 49 weeks after the first exposure to asbestos vs. naïve animals. d Goldner staining of mesothelioma grown in naïve vs. asbestos-exposed mice prognosis in TCGA mesothelioma samples (Supplementary Figure 8).

Beachy et al. [50] proposed that chronic tissue repair activates stem cell signaling pathways to regenerate the tissue and that oncogenic events may occur due to persistent system stimulation, leading to the formation of a tumor. For the time being, the cell types that proliferate upon exposure to asbestos fibers are not known. Already in the 1980s it has been claimed that mesothelioma originate from the transformation of multipotent connective tissue stem cells that can differentiate into most mesenchymal patterns [51]. In MexTag mice where the SV40 T antigen (Tag) is under the control of the mesothelin promoter and which develop mesothelioma tumors upon exposure to asbestos fibers, Tag is not detected in unexposed mice [52]. Mesothelin is a target of YAP activation [53] and we observed that mesothelin expression increased in both, inflamed mesothelium and tumors. This is associated with the accumulation of mesothelin-expressing mesothelial precursors in the lavage of asbestos-exposed mice, consistent with a previous study where a mesothelin-expressing population different from macrophages has been described to accumulate in the peritoneal lavage after mesothelium injury [18]. In order to determine the contribution of the accumulation of the precursor population, it would be necessary to perform functional studies for example using mesothelin-deficient mice. Mesothelin-deficient mice have a normal phenotype [54] and to our knowledge no study has been performed using mesothelin-deficient mice exposed to asbestos to check whether mesothelin deficiency would affect tumor development. However, to address this question it should be kept in mind that the penetrance of the disease after exposure to 
asbestos fibers in C57BL/6 $\mathrm{J}$ genetic background is unexpectedly low (10\% in this study using $\mathrm{Nf} 2$ heterozygotes mice), consistent with other studies $[55,56]$, therefore further refinements of the model would be necessary before starting such an investigation.

One of the highest upregulated genes after exposure to asbestos was Argl consistent with the observation of a CD90/Arginase-1-positive mesothelial cell population, able to inhibit $\mathrm{T}$ cell activation, within intraperitoneal cells recovered from human samples [57]. Therefore, it seems possible that mesothelial cells themselves contribute to immunosuppressive signaling.

Although an asbestos signature was present in preneoplastic tissues, some mice did not develop a tumor but maintained the predisposition to promote tumor growth highlighting the importance of the environment. This is also supported by the observation that $<50 \%$ of human mesothelioma grow in NOD/SCID mice [58], (Felley-Bosco, unpublished), possibly due to an unfavorable growth microenvironment. As mentioned previously, macrophages are recruited to the site of damage after administration of a single dose of asbestos fibers [2] and it has been recently confirmed that this population is the most abundant after intraperitoneal administration of asbestos in C57Bl/6J mice [55]. A role for macrophages in asbestos-related chronic inflammation had been suggested in studies, where "frustrated phagocytosis" induced by exposure of macrophages to asbestos increased the secretion of mature interleukin- $1 \beta$ by activating the complex Nod-like receptor-pyrin-domaincontaining-3 (Nlrp3), procaspase-1, and the apoptosis speck-like protein containing a CARD-adapter (Asc), which bridges interactions between the former proteins [59]. In later studies, interleukin- $1 \beta$ production was significantly decreased in the Nlrp3-deficient mice or Asc hemizygote mice after the administration of asbestos, but mice displayed a similar incidence of malignant mesothelioma as wild-type mice [60, 61], although in Asc hemizygote mice a delay in mesothelioma appearance was observed. Because Asc forms complexes not only with NLRP3 but also, e.g., with AIM2 [62], which senses DNA breaks, it might be worth to investigate whether AIM2 deficiency has an influence on mesothelioma development. Indeed, in another mesothelioma model induced by asbestos in $\mathrm{Nf2+I}$; $C d k n 2 a+l-$ mice in a FVB genetic background, blockage of IL- $1 \beta$ using IL1 $\beta$ receptor antagonist anakinra delayed mesothelioma development [61], indicating a promoting role of IL1 $\beta$.

Besides experimental models, tumor-associated macrophages are a major component of the immune cell infiltration of the tumor microenvironment in mesothelioma patients and the presence of "M2"-polarized macrophages is associated with the worst outcome [63, 64]. Recent studies have demonstrated that pleural effusions contain "M2"polarized macrophages $[65,66]$, which inversely correlated with $\mathrm{T}$ cell in vivo and suppressed T-cell proliferation in vitro [66]. This is consistent with recently described recruitment after tissue injury of cavity macrophages, which then become "M2" polarized [67]. This would also be consistent with the resident macrophage self-renewal signature that we observed in our study.

In conclusion, our comprehensive analysis of loss of homeostasis in the mesothelial environment in asbestosexposed mice during tumor development suggest a progressive activation of YAP/TAZ-dependent gene transcription, RNA-editing accumulation of single nucleotide variations and a possible role for immunosuppressive macrophages and/or mesothelial precursor cells in tumor development.

\section{Material and methods}

\section{Experimental model}

C57B1/6J and B6;129S2-Nf2 ${ }^{\text {tm1Tyj } / J ~(h t t p s: / / w w w . j a x . o r g / ~}$ strain/008190) mice were obtained from Jackson Laboratories (Bar Harbor, Maine). Nf $2+/-$ mice were backcrossed for $\geq 6$ generations on a $\mathrm{C} 57 \mathrm{~B} 1 / 6 \mathrm{~J}$ genetic background. All experiments were performed with permission of the local animal care committee (Canton of Fribourg, Switzerland) and according to the present Swiss law. Unio Internationale Contra Cancrum (UICC)-grade crocidolite asbestos was obtained from SPI Supplies (West Chester, PA). Fibers were suspended in sterile $\mathrm{NaCl}(0.9 \%)$ triturated ten times through a 22-Gauge needle to obtain a homogenous suspension and injected ( $400 \mu \mathrm{g} /$ mouse) into 6 - 8 -weeks-old mice ( $\mathrm{n}=50,33$ male, 17 female), every 3 weeks for a total of eight rounds. Sham mice ( $n=37,19$ male, 18 female) were injected with saline. Mice were monitored for tumor formation and sacrificed either 33 weeks after the first crocidolite injection or some animals that had remained tumor-free were used in a challenging experiment 49 weeks after the first exposure to asbestos. RN5 cells $\left(1 \times 10^{6}\right)$, which were derived from one of the tumors [68], were injected s.c. and development of tumor growth was recorded. Complete necropsies were performed on mice euthanized by inhalation of $\mathrm{CO}_{2}$ collecting peritoneal lavage, scraped mesothelium, spleen, liver, diaphragm, and tumor masses. Histopathological diagnosis and analysis was performed on paraffin-embedded samples.

\section{Flow cytometry}

The abdominal cavity was washed with $10 \mathrm{ml}$ of phosphatebuffered saline (PBS). Cells obtained by this procedure were pelleted and supernatant was removed and stored at $-80{ }^{\circ} \mathrm{C}$ for later cytokine analysis. Spleens were placed into 
ice-cold PBS containing 1\% FBS. All samples were passed through $70 \mu \mathrm{m}$ cell strainer to achieve single cells. ACK lysis buffer (Invitrogen, Carlsbad, CA) was added to spleen samples. Flow cytometer analysis was carried out as previously described [12] with the following antibodies: MHC II (I-A, Clone: NIMR-4), CD68 (LSBio, Seattle, WA)FITC, F4/80 (Clone: BM8)-APC, CD34 (Clone: RAM34; BD Pharmagen)-PE, CD90.1 (Thy-1, Clone: HIS51; BD Pharmagen)-APC, mesothelin (MSLN, Clone: 295D; LSBio)-PE, mesothelin (MSLN, clone 295D and clone 35B, rat IgG2ak primary unconjugated; MBL Medical \& Biological Laboratories Co., Japan), CD3e (clone: 145-2C11)PE-Cy7, CD4 (clone: RM4-5)-PE, CD8 $\alpha$ (clone: 53-6.7)APC and CD20 (Clone: AISB12)-PE. All antibodies and isotypes were purchased from eBioscience or BioLegend (San Diego, CA) otherwise stated elsewhere. Both antimesothelin antibodies used in this study were derived using as antigen oncostatin-dependent intraembryonic aortagonad-mesonephros region-derived LO cells [69]. CloneB35 has been recently thoroughly characterized [70] and provided the same profile as clone 295D (Supplementary Figure 9).

\section{Immunohistochemistry}

Immunohistochemistry was performed as previously described [71] using the following antibodies: anti-wide spectrum Cytokeratin (Ab9377), vimentin (Ab92547), podoplanin (clone 8.1.1), WT-1 (sc-192), mesothelin (mAb 295D), YAP (4912), Ki-67 (GTX16667), arginase I (clone $\mathrm{H}-52$ ), and F4/80 (123102).

\section{Measurement of cytokines/chemokines}

Peritoneal lavage fluids were concentrated by ultrafiltration through a low-adsorption polyethersulfonate (PES) membrane (mol. mass. cutoff $3 \mathrm{kDa}$, concentrator Pierce PES $3 \mathrm{~K}$, Thermofisher). The concentration factor was noted for each fluid and used in the calculation of the results. The average concentration factor was 7 with a range from 4 to 10 and it was used to calculate non-concentrated levels. A Bio-Plex mouse cytokine assay (BioRad) for simultaneous quantification of the concentrations of several signaling molecules (IL-6, IL-10, G-CSF, GM-CSF, IFN- $\gamma$, CXCl1, CCL2, CCL5, and VEGF) was run according to the recommended procedure.

\section{Library preparation, cluster generation, and sequencing}

The quantity and quality of the isolated RNA was determined with a Qubit $^{\circledR}$ (1.0) Fluorometer (Life Technologies, California, USA) and a Bioanalyzer 2100 (Agilent,
Waldbronn, Germany). The TruSeq Stranded mRNA Sample Prep Kit (Illumina, Inc., California, USA) was used in the succeeding steps. Briefly, total RNA samples (100 ng) were ribosome depleted and then reverse-transcribed into double-stranded cDNA with actinomycin added during first-strand synthesis. The cDNA samples were fragmented, end-repaired, and polyadenylated before ligation of TruSeq adapters. The adapters contain the index for multiplexing. Fragments containing TruSeq adapters on both ends were selectively enriched with PCR. The quality and quantity of the enriched libraries were validated using Qubit $^{\circledR}$ (1.0) Fluorometer and the Bioanalyzer 2100 (Agilent, Waldbronn, Germany). The product is a smear with an average fragment size of $\sim 360 \mathrm{bp}$. The libraries were normalized to $10 \mathrm{nM}$ in Tris-HCl $10 \mathrm{mM}, \mathrm{pH} 8.5$ with $0.1 \%$ Tween 20 .

The TruSeq SR Cluster Kit v3-cBot-HS or TruSeq PE Cluster Kit v3-cBot-HS (Illumina, Inc., California, USA) was used for cluster generation using $8 \mathrm{pM}$ of pooled normalized libraries on the cBOT. Sequencing was performed on the Illumina HiSeq 2000 paired end at $2 \times 101$ bp or single end $100 \mathrm{bp}$ using the TruSeq SBS Kit v3-HS (Illumina, Inc., California, USA). Adapter sequences are available upon request. RNA-seq data are deposited in the European Nucleotide Archive (http://www.ebi.ac.uk/ena/da ta/view/PRJEB15230).

\section{RNA-seq analysis}

Read data were quality controlled with Fastqc and FastqScreen to confirm that reads are of high quality and free of contaminants. Read-alignment was done using the STARaligner [72]. As reference we used the Ensembl genome build GRCm38.p3. Gene expression values were computed with the function featureCounts from the $\mathrm{R}$ package Rsubread [73]. Differential expression was computed using the generalized linear model implemented in the Bioconductor package DESeq2 [74].

Variant analysis was performed using the GATK (software.broadinstitute.org) software following the RNA-seq best practices. Specifically, we looked at variants on transcript regions and ignored sites with $<2$ reads supporting the $\mathrm{SNV}$. We also excluded variants in Ig loci since they are generated by well known somatic hypermutation mechanisms which would be a potentially confounding effect. In order to identify $A$ to $G$ mutation due to RNA-editing events, predicted A to I sites from http://rnaedit.com/dow nload/ were translated to mm10 coordinates. Gene set expression enrichment analysis was performed using online available software (http://software.broadinstitute.org/gsea/ msigdb/index.jsp) [31].

Expression changes in mouse tumors compared to nontumor tissues were compared to expression changes in the study GSE51024 [38] which compared mesothelioma 
tumors vs. normal tissue. The analysis was performed with Geo2R, which makes use of the R/Bioconductor package limma. Log2 fold changes, nominal $p$ values, and Benjamini-Hochberg FDR were calculated by Geo2R/ Limma.

FPKM data corresponding to gene symbols within given GO terms were retrieved from the normalized data frame, if the $p$ value was $<0.01$ and the absolute value of the $\log 2-$ ratio was $>1$ for the comparison among tum and asbestosexposed tissue and mean FPKM was greater than 1 in at least one of the three sample groups.

Selected gene expression analysis (primers in Supplementary Table 4) was performed as previously described [71].

\section{Investigation of RNA editing}

Expression of ADAR and ADARB1 was investigated by western blot analysis performed as previously described [75] using anti-ADAR (HPA003890) and anti-ADARB1 (HPA018277) antibodies (Sigma Life Science) in NCIH226 (from ATCC) and SPC111 mesothelioma cells (authenticated by STR profiling) grown as previously described [76]. Cells are routinely screened for mycoplasma contamination. Azin1 RNA editing was characterized using a recently developed sensitive RNA editing site-specific quantitative RT_PCR [23] after ADAR or ADARB1 silencing achieved using Dharmacon reagents as previously described [36].

\section{Bap1 and Nf2 characterization in tumor cells}

Relative quantification of gene Bapl and Nf2 copy number [28] was evaluated using genomic DNA from RN5-tumor cells compared to non-tumor cells (primers are listed in Supplementary Table 5). Protein levels were evaluated by western blot using anti Nf2 (sc-332) and anti-Bap1 (Sc28383) antibodies (Santa-Cruz).

\section{Statistical analysis}

Each study was designed to use the minimum number of mice required to obtain informative results (meaning quantitative data amenable to statistical analysis) and sufficient material for subsequent studies such as cytokine determination, immunohistochemistry, and expression profiling. No specific statistical tests were used to predetermine the sample size; our previous experience with subcutaneous tumor models and pilot experiments provided guidance about the adequate number of mice that would provide significant results. Typically, we employed experimental cohorts of at least five to six mice. In several cases, more mice were enrolled to provide sufficient material for independent analysis involving different procedure (for example cytokine determination, histology, RNA analysis). Unpaired Student's $t$-test, Mann-Whitney $\mathrm{U}$ or Kruskal-Wallis and Fisher's Exact test were generally used. Error bars indicate the standard error of the mean. Statistical analysis was performed using Prism 6 (Graphpad).

Acknowledgements We are grateful to Dr. Marie-Claude Jaurand and Dr. Maries van den Broek for critical reading of the manuscript. We are also grateful to Manuel Ronner, Gabriela Ziltener, Janine Worthmüller, Simone Eichenberger, Marlène Sanchez for skillful assistance. We also thank the Princess Margaret Hospital Foundation and the Toronto General and Western Hospital Foundation to MdP, the Stiftung für Angewandte Krebsforschung to EFB. We thank Dr. Roman Briskine for running the SNV analysis workflow.

Funding The project is financed by the Swiss National Science Foundation Sinergia Grant CRSII3 \#147697.

\section{Compliance with ethical standards}

Conflict of interest The authors declare that they have no competing interests.

Open Access This article is licensed under a Creative Commons Attribution-NonCommercial-NoDerivatives 4.0 International License, which permits any non-commercial use, sharing, distribution and reproduction in any medium or format, as long as you give appropriate credit to the original author(s) and the source, and provide a link to the Creative Commons license. You do not have permission under this license to share adapted material derived from this article or parts of it. The images or other third party material in this article are included in the article's Creative Commons license, unless indicated otherwise in a credit line to the material. If material is not included in the article's Creative Commons license and your intended use is not permitted by statutory regulation or exceeds the permitted use, you will need to obtain permission directly from the copyright holder. To view a copy of this license, visit http://creativecommons.org/licenses/by-nc-nd/4.0/.

\section{References}

1. Wagner JC. Experimental production of mesothelial tumours of the pleura by implantation of dusts in laboratory animals. Nature. 1962;196:180-1.

2. Moalli PA, MacDonald JL, Goodglick LA, Kane AB. Acute injury and regeneration of the mesothelium in response to asbestos fibers. Am J Pathol. 1987;128:426-45.

3. Mapara MY, Sykes M. Tolerance and cancer: mechanisms of tumor evasion and strategies for breaking tolerance. J Clin Oncol. 2004;22:1136-51.

4. Banchereau J, Palucka AK. Dendritic cells as therapeutic vaccines against cancer. Nat Rev Immunol. 2005;5:296-306.

5. Tartour E, Pere H, Maillere B, Terme M, Merillon N, Taieb J, et al. Angiogenesis and immunity: a bidirectional link potentially relevant for the monitoring of antiangiogenic therapy and the development of novel therapeutic combination with immunotherapy. Cancer Metastasis Rev. 2011;30:83-95.

6. Jinushi M, Chiba S, Yoshiyama H, Masutomi K, Kinoshita I, Dosaka-Akita $\mathrm{H}$, et al. Tumor-associated macrophages regulate tumorigenicity and anticancer drug responses of cancer stem/initiating cells. Proc Natl Acad Sci USA. 2011;108:12425-30 
7. Gabrilovich DI, Nagaraj S. Myeloid-derived suppressor cells as regulators of the immune system. Nat Rev Immunol. 2009;9:162-74.

8. Cherkassky L, Morello A, Villena-Vargas J, Feng Y, Dimitrov DS, Jones DR, et al. Human CAR T cells with cell-intrinsic PD-1 checkpoint blockade resist tumor-mediated inhibition. J Clin Invest. 2016;126:3130-44.

9. Khanna S, Thomas A, Abate-Daga D, Zhang J, Morrow B, Steinberg SM, et al. Malignant mesothelioma effusions are infiltrated by CD3 + T cells highly expressing PD-L1 and the PD-L1+ tumor cells within these effusions are susceptible to ADCC by the anti-PD-L1 antibody avelumab. J Thorac Oncol. 2016;11:1993-2005.

10. Veltman JD, Lambers ME, van Nimwegen M, Hendriks RW, Hoogsteden HC, Aerts JG, et al. COX-2 inhibition improves immunotherapy and is associated with decreased numbers of myeloid-derived suppressor cells in mesothelioma. Celecoxib influences MDSC function. BMC Cancer. 2010;10:464.

11. Wu L, Yun Z, Tagawa T, Rey-McIntyre K, Anraku M, de Perrot $M$. Tumor cell repopulation between cycles of chemotherapy is inhibited by regulatory T-cell depletion in a murine mesothelioma model. J Thorac Oncol. 2011;6:1578-86.

12. Wu L, Yun Z, Tagawa T, Rey-McIntyre K, de Perrot M. CTLA-4 blockade expands infiltrating $\mathrm{T}$ cells and inhibits cancer cell repopulation during the intervals of chemotherapy in murine mesothelioma. Mol Cancer Ther. 2012;11:1809-19.

13. Jean D, Thomas E, Manie E, Renier A, de Reynies A, Lecomte C, et al. Syntenic relationships between genomic profiles of fiberinduced murine and human malignant mesothelioma. Am J Pathol. 2011;178:881-94.

14. Altomare DA, Vaslet CA, Skele KL, De Rienzo A, Devarajan K, Jhanwar SC, et al. A mouse model recapitulating molecular features of human mesothelioma. Cancer Res. 2005;65:8090-5.

15. Fleury-Feith J, Lecomte C, Renier A, Matrat M, Kheuang L, Abramowski V, et al. Hemizygosity of $\mathrm{Nf} 2$ is associated with increased susceptibility to asbestos-induced peritoneal tumours. Oncogene. 2003;22:3799-805.

16. Jongsma J, van Montfort E, Vooijs M, Zevenhoven J, Krimpenfort $\mathrm{P}$, van der Valk M, et al. A conditional mouse model for malignant mesothelioma. Cancer Cell. 2008;13:261-71.

17. Foley-Comer AJ, Herrick SE, Al-Mishlab T, Prele CM, Laurent GJ, Mutsaers SE. Evidence for incorporation of free-floating mesothelial cells as a mechanism of serosal healing. J Cell Sci. 2002;115:1383-9.

18. Carmona R, Cano E, Grueso E, Ruiz-Villalba A, Bera TK, Gaztambide J, et al. Peritoneal repairing cells: a type of bone marrow derived progenitor cells involved in mesothelial regeneration. $\mathbf{J}$ Cell Mol Med. 2011;15:1200-9.

19. Rinkevich Y, Mori T, Sahoo D, Xu PX, Bermingham JR Jr, Weissman IL. Identification and prospective isolation of a mesothelial precursor lineage giving rise to smooth muscle cells and fibroblasts for mammalian internal organs, and their vasculature. Nat Cell Biol. 2012;14:1251-60.

20. Roca H, Varsos ZS, Sud S, Craig MJ, Ying C, Pienta KJ. CCL2 and interleukin- 6 promote survival of human $\mathrm{CD} 11 \mathrm{~b}+$ peripheral blood mononuclear cells and induce M2-type macrophage polarization. J Biol Chem. 2009;284:34342-54.

21. Nishikura K. A-to-I editing of coding and non-coding RNAs by ADARs. Nat Rev Mol Cell Biol. 2016;17:83-96.

22. Chen L, Li Y, Lin CH, Chan TH, Chow RK, Song Y, et al. Recoding RNA editing of AZIN1 predisposes to hepatocellular carcinoma. Nat Med. 2013;19:209-16.

23. Crews LA, Jiang Q, Zipeto MA, Lazzari E, Court AC, Ali S, et al. An RNA editing fingerprint of cancer stem cell reprogramming. J Transl Med. 2015;13:52.
24. Sekido Y, Pass HI, Bader S, Mew DJ, Christman MF, Gazdar AF, et al. Neurofibromatosis type 2 (NF2) gene is somatically mutated in mesothelioma but not in lung cancer. Cancer Res. 1995;55:1227-31.

25. Bianchi AB, Mitsunaga SI, Cheng JQ, Klein WM, Jhanwar SC, Seizinger B, et al. High frequency of inactivating mutations in the neurofibromatosis type 2 gene (NF2) in primary malignant mesotheliomas. Proc Natl Acad Sci USA. 1995;92:10854-8.

26. Bott M, Brevet M, Taylor BS, Shimizu S, Ito T, Wang L, et al. The nuclear deubiquitinase BAP1 is commonly inactivated by somatic mutations and 3p21.1 losses in malignant pleural mesothelioma. Nat Genet. 2011;43:668-72.

27. Bueno R, Stawiski EW, Goldstein LD, Durinck S, De Rienzo A, Modrusan Z, et al. Comprehensive genomic analysis of malignant pleural mesothelioma identifies recurrent mutations, gene fusions and splicing alterations. Nat Genet. 2016;48:407-16.

28. Moore DA, Saldanha G, Ehdode A, Potter L, Dyall L, Bury D, et al. Accurate detection of copy number changes in DNA extracted from formalin-fixed, paraffin-embedded melanoma tissue using duplex ratio tests. J Mol Diagn. 2013;15:687-94.

29. Dong J, Feldmann G, Huang J, Wu S, Zhang N, Comerford SA, et al. Elucidation of a universal size-control mechanism in Drosophila and mammals. Cell. 2007;130:1120-33.

30. Zhao B, Ye X, Yu J, Li L, Li W, Li S, et al. TEAD mediates YAPdependent gene induction and growth control. Genes Dev. 2008;22:1962-71.

31. Subramanian A, Tamayo P, Mootha VK, Mukherjee S, Ebert BL, Gillette MA, et al. Gene set enrichment analysis: a knowledgebased approach for interpreting genome-wide expression profiles. Proc Natl Acad Sci USA. 2005;102:15545-50.

32. Fujii M, Toyoda T, Nakanishi H, Yatabe Y, Sato A, Matsudaira Y, et al. TGF-beta synergizes with defects in the Hippo pathway to stimulate human malignant mesothelioma growth. J Exp Med. 2012;209:479-94.

33. Supek F, Bosnjak M, Skunca N, Smuc T. REVIGO summarizes and visualizes long lists of gene ontology terms. PLoS ONE. 2011;6:e21800.

34. Broad Institute TCGA Genome Data Analysis Center (2014): PARADIGM pathway analysis of mRNASeq expression and copy number data. Broad Institute of MIT and Harvard. 2014. http:// gdac.broadinstitute.org/runs/analyses_2014_10_17/reports/cancer/MESO-TP/Pathway_Par-

adigm_RNASeq_And_Copy_Number/nozzle.html. (Accessed June 2017).

35. Dixit R, Ai X, Fine A. Derivation of lung mesenchymal lineages from the fetal mesothelium requires hedgehog signaling for mesothelial cell entry. Development. 2013;140:4398-406.

36. Shi Y, Moura U, Opitz I, Soltermann A, Rehrauer H, Thies S, et al. Role of hedgehog signaling in malignant pleural mesothelioma. Clin Cancer Res. 2012;18:4646-56.

37. Pass HI, Stevens EJ, Oie H, Tsokos MG, Abati AD, Fetsch PA, et al. Characteristics of nine newly derived mesothelioma cell lines. Ann Thorac Surg. 1995;59:835-44.

38. Suraokar MB, Nunez MI, Diao L, Chow CW, Kim D, Behrens C, et al. Expression profiling stratifies mesothelioma tumors and signifies deregulation of spindle checkpoint pathway and microtubule network with therapeutic implications. Ann Oncol. 2014;25:1184-92.

39. Tamminen JA, Parviainen V, Ronty M, Wohl AP, Murray L, Joenvaara $\mathrm{S}$, et al. Gremlin-1 associates with fibrillin microfibrils in vivo and regulates mesothelioma cell survival through transcription factor slug. Oncogenesis. 2013;2:e66.

40. Sica A, Mantovani A. Macrophage plasticity and polarization: in vivo veritas. J Clin Invest. 2012;122:787-95. 
41. Soucie EL, Weng Z, Geirsdottir L, Molawi K, Maurizio J, Fenouil $\mathrm{R}$, et al. Lineage-specific enhancers activate self-renewal genes in macrophages and embryonic stem cells. Science. 2016;351: aad5510.

42. George CX, Samuel CE. Characterization of the 5'-flanking region of the human RNA-specific adenosine deaminase ADAR1 gene and identification of an interferon-inducible ADAR1 promoter. Gene. 1999;229:203-13.

43. Mizuno T, Murakami H, Fujii M, Ishiguro F, Tanaka I, Kondo Y, et al. YAP induces malignant mesothelioma cell proliferation by upregulating transcription of cell cycle-promoting genes. Oncogene. 2012;31:5117-22.

44. Jiang Q, Crews LA, Holm F, Jamieson CHM. RNA editingdependent epitranscriptome diversity in cancer stem cells. Nat Rev Cancer. 2017;17:381-92.

45. Mori M, Triboulet R, Mohseni M, Schlegelmilch K, Shrestha K, Camargo FD, et al. Hippo signaling regulates microprocessor and links cell-density-dependent miRNA biogenesis to cancer. Cell. 2014;156:893-906.

46. Dupont S, Morsut L, Aragona M, Enzo E, Giulitti S, Cordenonsi $\mathrm{M}$, et al. Role of YAP/TAZ in mechanotransduction. Nature. 2011;474:179-83.

47. Musah S, Wrighton PJ, Zaltsman Y, Zhong X, Zorn S, Parlato $M B$, et al. Substratum-induced differentiation of human pluripotent stem cells reveals the coactivator YAP is a potent regulator of neuronal specification. Proc Natl Acad Sci USA. 2014;111:13805-10.

48. Swift J, Ivanovska IL, Buxboim A, Harada T, Dingal PC, Pinter J, et al. Nuclear lamin-A scales with tissue stiffness and enhances matrix-directed differentiation. Science. 2013;341:1240104.

49. Piccolo S, Dupont S, Cordenonsi M. The biology of YAP/TAZ: hippo signaling and beyond. Physiol Rev. 2014;94:1287-312.

50. Beachy PA, Karhadkar SS, Berman DM. Tissue repair and stem cell renewal in carcinogenesis. Nature. 2004;432:324-31.

51. Gormley IP, Bolton RE, Brown G, Davis JM, Donaldson K. Studies on the morphological patterns of asbestos induced mesotheliomas in vivo and in vitro. Carcinogenesis. 1980;1:219-31.

52. Robinson C, Walsh A, Larma I, O'Halloran S, Nowak AK, Lake RA. MexTAg mice exposed to asbestos develop cancer that faithfully replicates key features of the pathogenesis of human mesothelioma. Eur J Cancer. 2010;47:151-61.

53. Ren YR, Patel K, Paun BC, Kern SE. Structural analysis of the cancer-specific promoter in mesothelin and in other genes overexpressed in cancers. J Biol Chem. 2011;286:11960-9.

54. Bera TK, Pastan I. Mesothelin is not required for normal mouse development or reproduction. Mol Cell Biol. 2000;20:2902-6.

55. Huaux F, d'Ursel de Bousies V, Parent MA, Orsi M, Uwambayinema F, Devosse R, et al. Mesothelioma response to carbon nanotubes is associated with an early and selective accumulation of immunosuppressive monocytic cells. Part Fibre Toxicol. 2016;13:46

56. Napolitano A, Pellegrini L, Dey A, Larson D, Tanji M, Flores EG, et al. Minimal asbestos exposure in germline BAP1 heterozygous mice is associated with deregulated inflammatory response and increased risk of mesothelioma. Oncogene. 2015;35:1996-2002.

57. Kitayama J, Emoto S, Yamaguchi H, Ishigami H, Yamashita H, Seto Y, et al. CD90(+)CD45(-) intraperitoneal mesothelial-like cells inhibit $\mathrm{T}$ cell activation by production of arginase I. Cell Immunol. 2014;288:8-14.

58. Tsao MS, Wu L, Allo G, John T, Li M, Tagawa T, et al. Patientderived xenograft establishment from human malignant pleural mesothelioma. Clin Cancer Res. 2016;23:1060-7.
59. Dostert C, Petrilli V, Van Bruggen R, Steele C, Mossman BT, Tschopp J. Innate immune activation through Nalp3 inflammasome sensing of asbestos and silica. Science. 2008;320:674-7.

60. Chow MT, Tschopp J, Moller A, Smyth MJ. NLRP3 promotes inflammation-induced skin cancer but is dispensable for asbestosinduced mesothelioma. Immunol Cell Biol. 2012;90:983-6.

61. Kadariya Y, Menges CW, Talarchek J, Cai KQ, Klein-Szanto AJ, Pietrofesa RA, et al. Inflammation-related IL1beta/IL1R signaling promotes the development of asbestos-induced malignant mesothelioma. Cancer Prev Res (Phila). 2016;9:406-14.

62. Strowig T, Henao-Mejia J, Elinav E, Flavell R. Inflammasomes in health and disease. Nature. 2012;481:278-86.

63. Cornelissen R, Lievense LA, Maat AP, Hendriks RW, Hoogsteden HC, Bogers AJ, et al. Ratio of intratumoral macrophage phenotypes is a prognostic factor in epithelioid malignant pleural mesothelioma. PLoS ONE. 2014;9:e106742.

64. Burt BM, Rodig SJ, Tilleman TR, Elbardissi AW, Bueno R, Sugarbaker DJ. Circulating and tumor-infiltrating myeloid cells predict survival in human pleural mesothelioma. Cancer. 2011;117:5234-44.

65. Chene AL, d'Almeida S, Blondy T, Tabiasco J, Deshayes S, Fonteneau JF, et al. Pleural effusions from patients with mesothelioma induce recruitment of monocytes and their differentiation into M2 macrophages. J Thorac Oncol. 2016;11:1765-73.

66. Lievense LA, Cornelissen R, Bezemer K, Kaijen-Lambers ME, Hegmans JP, Aerts JG. Pleural effusion of patients with malignant mesothelioma induces macrophage-mediated $\mathrm{T}$ cell suppression. $\mathrm{J}$ Thorac Oncol. 2016;11:1755-64.

67. Wang J, Kubes P. A reservoir of mature cavity macrophages that can rapidly invade visceral organs to affect tissue repair. Cell. 2016;165:668-78.

68. Blum W, Pecze L, Felley-Bosco E, Worthmuller-Rodriguez J, Wu L, Vrugt B, et al. Establishment of immortalized murine mesothelial cells and a novel mesothelioma cell line. In vitro Cell Dev Biol Anim. 2015;51:714-21.

69. Hara T, Nakano Y, Tanaka M, Tamura K, Sekiguchi T, Minehata $\mathrm{K}$, et al. Identification of podocalyxin-like protein 1 as a novel cell surface marker for hemangioblasts in the murine aorta-gonadmesonephros region. Immunity. 1999;11:567-78.

70. Zervos E, Agle S, Freistaedter AG, Jones GJ, Roper RL. Murine mesothelin: characterization, expression, and inhibition of tumor growth in a murine model of pancreatic cancer. J Exp Clin Cancer Res. 2016;35:39.

71. Frei C, Opitz I, Soltermann A, Fischer B, Moura U, Rehrauer H, et al. Pleural mesothelioma side populations have a precursor phenotype. Carcinogenesis. 2011;32:1324-32.

72. Dobin A, Davis CA, Schlesinger F, Drenkow J, Zaleski C, Jha S, et al. STAR: ultrafast universal RNA-seq aligner. Bioinformatics. 2013;29:15-21.

73. Liao Y, Smyth GK, Shi W. The Subread aligner: fast, accurate and scalable read mapping by seed-and-vote. Nucleic Acids Res. 2013;41:e108.

74. Love MI, Huber W, Anders S. Moderated estimation of fold change and dispersion for RNA-seq data with DESeq2. Genome Biol. 2014;15:550.

75. Parrotta R, Okonska A, Ronner M, Weder W, Stahel R, Penengo $\mathrm{L}$, et al. A novel BRCA1-associated protein-1 isoform affects response of mesothelioma cells to drugs impairing BRCA1mediated DNA repair. J Thorac Oncol. 2017;12:1309-1319.

76. Echeverry N, Ziltener G, Barbone D, Weder W, Stahel RA, Broaddus VC, et al. Inhibition of autophagy sensitizes malignant pleural mesothelioma cells to dual PI3K/mTOR inhibitors. Cell Death Dis. 2015;6:e1757. 